\title{
El peso de las lenguas cooficiales en el acceso a la función pública: la evolución de la jurisprudencia hasta la STC 253/2005, de 15 de noviembre
}

\author{
Patricia Fabeiro Fidalgo \\ Profesora de Derecho Constitucional UNED
}

Sumario: INTRODUCCIÓN. 1. La necesidad constitucional de valorar el conocimiento de la lengua cooficial en relación con la función pública que sirve en la Comunidad Autónoma dotada de cooficialidad versus la imposibilidad constitucional de hacerlo. a) Jurisprudencia constitucional: STC 76/1983, de 5 de agosto. b) Jurisprudencia del Tribunal Supremo hasta 1986. 2. La concreta trascendencia que cabe asignar al conocimiento de la lengua cooficial para el acceso a la función pública que sirve en la Comunidad Autónoma dotada de cooficialidad: su valor de mérito con carácter general y de requisito lingüístico para ciertas plazas. a) Jurisprudencia constitucional: STC 82/1986, de 26 de junio. b) Jurisprudencia del Tribunal Supremo a partir de 1986. 3. El conocimiento de la lengua autonómica como requisito para el acceso a la función pública: requisito general versus requisitos para ciertas plazas. a) Jurisprudencia constitucional: STC 46/1991, de 28 de febrero. b) Jurisprudencia del Tribunal Supremo mantenimiento de la línea iniciada en el año 1986 y definitivamente asentada en el año 1989. c) La última Jurisprudencia constitucional: STC 10-10-2005, de 15 de noviembre.

\section{INTRODUCCIÓN}

El derecho constitucional de los ciudadanos a ser atendidos en la lengua autonómica en sentido débil —no precisar traducción o intérprete para dirigir comunicaciones a la Administración Pública, que no pueden ser rechazadas - o fuerte ${ }^{1}$ - recibir contestación en la misma-, que se desprenden del art. 3 de la Carta magna y el artículo concordante de los respectivos EEAA, exigen que la Administración esté adaptada al bilingüismo, y por ende otorgar relevancia jurídica al conocimiento del idioma cooficial al objeto del ingreso y/o la provisión de plazas en la función pública radicada en las Comunidades Autónomas con doble oficialidad.

Reza así el mentado art. 3 de nuestra Ley Fundamental:

«1. El castellano es la lengua española oficial del Estado. Todos los españoles tienen el deber de conocerla y el derecho de usarla.

2. Las demás lenguas españolas serán también oficiales en las respectivas Comunidades Autónomas de acuerdo con sus Estatutos.

3. La riqueza de las distintas modalidades lingüísticas de España es un patrimonio cultural que será objeto de especial respeto y protección».

\footnotetext{
${ }^{1}$ Empleo aquí la terminología utilizada por Alberti RovirA, E., «Bilingüismo», Temas básicos de Derecho Constitucional, Tomo I, Cívitas, pp. 99 y ss.
} 
El deber de conocer el castellano previsto en el apartado $10^{\circ}$ del art. $3 \mathrm{CE}$, ni para el caso de la Administración, ni para el del Poder judicial, permite obviar tal requerimiento de acomodación a la cooficialidad que impone el derecho de utilizar la lengua oficial de preferencia del ciudadano.

Pero lo que ahora comprobaremos es que tampoco tendrán el efecto de impedirlo el derecho fundamental de igualdad en el acceso a los cargos públicos que alberga el art. 23 de la Carta magna, íntimamente vinculado con el art. 14, ni el principio de mérito y capacidad para el acceso a la función pública que cobija el art. 103; mas sí gozarán de la eficacia de erigirse en parámetros determinantes en la precisión del valor que a tal competencia idiomática quepa constitucionalmente atribuir por el legislador en lo que hace al ingreso y/o provisión de plazas en la función pública de las Comunidades Autónomas con doble oficialidad.

En el presente estudio analizaremos la posición jurisprudencial al respecto, su evolución y el estado actual de la cuestión, que según dejaremos constatado al término de este artículo, a nuestro juicio se ha pacificado con la STC de 10 de octubre de 2005; resolución con la cual la postura del Máximo intérprete de la Constitución y la del Tribunal Supremo devienen prácticamente convergentes.

\section{La necesidad constitucional de valorar el conocimiento de la lengua cooficial en relación con la función pública que sirve en la Comunidad Autónoma dotada de cooficialidad versus la im- posibilidad constitucional de hacerlo}

\section{a) Jurisprudencia constitucional: STC 76/1983, de 5 de agosto}

A principios de los años 80 ya la Ley Orgánica de Armonización del Proceso Autonómico (L.O.A.P.A) disponía que en la provisión de las vacantes que se produzcan en los puestos de trabajo correspondientes a los servicios transferidos, en las CCAA donde exista, además de la lengua del Estado, otra lengua oficial, la Administración del Estado deberá tener en cuenta este hecho.

Por su parte el Alto tribunal, con ocasión del recurso previo de inconstitucionalidad contra esta Ley, resuelve en la STC 76/1983, de 5 de agosto, adoptando «una interpretación sistemática de los preceptos constitucionales y estatutarios», que el conocimiento de la lengua propia habrá de considerarse como mérito para la provisión de vacantes, y que sólo es admisible su obligatoriedad en relación con la Administración considerada en su conjunto, no en lo que hace a cada uno de sus individuos integrantes, y todo «como modo de garantizar el derecho a usarla por parte de los ciudadanos» (Fundamento Jurídico 42). 
EL PESO DE LAS LENGUAS COOFICIALES EN EL ACCESO A LA FUNCIÓN PÚBLICA...

Ahondando en este último inciso - a saber la causa y finalidad de asignar trascendencia jurídica al dominio de la lengua vernácula por el personal al servicio de la Administración- explica en lo concerniente a la consideración de mérito que efectúa el art. 32 .2, a) de la mentada Ley, [art. 25.2.a) del texto vigente], que «no tiene su fundamento en la implantación real de la lengua en cuestión, sino en la necesaria garantía del derecho a usarla, por lo que la frase final del apartado a) del art. 32.2 «en función de la implantación real de la misma», ha de considerarse inconstitucional [...]».

Con estas palabras, el Alto guardián de la Constitución consagra la obligación contitucional de que la Administración sita en la Comunidad Autónoma con cooficialidad esté en posición o condición de hacer posible el derecho de usar la lengua regional que tienen todos los ciudadanos en el territorio de aquélla.

Cosa distinta es que la resolución asuma la perspectiva de que el conocimiento de la lengua propia de una Comunidad como obligación lo es de la Administración en su conjunto, mas no de todos y cada uno de los funcionarios que la integran. Con lo que viene a referirse a la existencia de una obligación institucional pero no individual, al bilingüismo de los servicios pero no de los funcionarios: el Tribunal Constitucional habla del deber constitucional de toda Administración sita en la Comunidad Autónoma con cooficialidad, cualquiera que sea, de estar preparada, de contar con funcionarios con competencia lingüística.

A tales efectos da por válida su valoración como mérito en la provisión de plazas, si bien nada obsta que pueda tener tal condición en los procesos de acceso, inclusive la de requisito para el ingreso en ciertas plazas.

Desde luego fue ésta la opción de la primera Ley de normalización linguiística, la Ley 10/1982, de 24 de noviembre, Básica de Normalización del Uso del Euskera, art. 14, hoy aun vigente, y de las posteriores, que aluden a la estimación del idioma autonómico como mérito y aun como requisito de acceso para determinadas plazas.

Asimismo podemos entender que fue lo que dispuso la Ley para la reforma de la Función Pública de 1984, en su art. 19, a tenor del cual (1) los procedimientos de selección «cuidarán especialmente la conexión entre el tipo de pruebas a superar y la adecuación a los puestos de trabajo que se hayan de desempeñar». Y (2) en las convocatorias para el acceso a la función pública, «las Administraciones públicas, en el respectivo ámbito de sus competencias, deberán prever la selección de funcionarios debidamente capacitados para cubrir los puestos de trabajo en las Comunidades Autónomas que gocen de dos lenguas oficiales». 


\section{b) Jurisprudencia del Tribunal Supremo hasta 1986}

A pesar del citado pronunciamiento de la Corte constitucional, y de la referida situación legislativa, el Tribunal Supremo desarrolla hasta 1986 una hermenéutica sobre la cooficialidad y su conexión con los principios de prohibición de discriminación en el acceso a las funciones y cargos públicos (arts. 14 y $23 \mathrm{CE}$ ), y de mérito y capacidad en el acceso a la función pública (art. 103.2 CE), que le conducen a repudiar toda valoración de la lengua autonómica en este ámbito del acceso a la función pública² .

En lo tocante a la cooficialidad, y según pone de relieve Cobreros Mendazona, para el Tribunal Supremo significa una asimilación en el trato de las lenguas, de modo que si dos son las lenguas oficiales no se puede valorar sólo una de ellas de suerte que «va contra la esencia de la cooficialidad el puntuar en las convocatorias el conocimiento del euskera y no el del castellano»; considera que la otra lengua es «olvidada o discriminada» ${ }^{3}$.

Sin embargo, como advierte el autor, es precisamente la cooficialidad lo que compele a que en las convocatorias se considere el manejo de la otra lengua, y lo que consiguientemente hace razonable esa atribución de relevancia jurídica a la diferencia en el reclutamiento del personal al servicio de las Administraciones Públicas. Haciendo énfasis el comentarista en que «con ello se puntúa el bilingüismo - conocer además del castellano la lengua propia-, esto es, el castellano no queda sin valorarse $»^{4}$.

Cuando en otras decisiones llega el órgano judicial a esta concepción de la cooficialidad — que la misma tiene este efecto de plantear la necesidad de personal bilingüe y de que consecuentemente se valore conocer la lengua autonómica para reclutarlo-, se le opone una concepción formal de la igualdad en el acceso a la función pública prevista en el art. $23 \mathrm{CE}$, que imposibilita aquello último, a saber su consideración para el acceso, pues hacerlo coloca en posición desfavorable a unos aspirantes respecto de otros.

Un proceder al que se objeta pasar por alto la doctrina que sobre el principio de igualdad sientan tanto el Tribunal Europeo de los Derechos Humanos como el Supremo intérprete de nuestro Texto Fundamental, y que en el caso de este último consiste en la imposibilidad de establecer una prelación o jerarquía entre el principio de doble oficialidad y el de igualdad en el acceso a la función pública, debiendo llegarse a una conciliación de ambos.

\footnotetext{
2 Sobre la postura del Tribunal Supremo Vid. Aurelio GuAITA MARTORELl, Lenguas de España y artículo 3. ${ }^{\circ}$ de la Constitución, Cívitas, Madrid, 1989. Figuran las siguientes SSTS: 25 de enero de 1985, 28 de marzo de 1985, 3 de mayo de 1985, 28 de julio de 1985 y 18 de octubre de 1986.

3 SSTS 3 mayo 1984, 28 marzo 1985, 25 enero 1984, 28 julio 1984.

${ }^{4}$ Cobreros Mendazona, E., «Cooficialidad lingüística y discriminación por razón de la lengua», REDA 42/1984, pp. 464, 466.
} 
EL PESO DE LAS LENGUAS COOFICIALES EN EL ACCESO A LA FUNCIÓN PÚBLICA...

Hacer un tratamiento de la igualdad específico y conforme a las diferentes realidades existentes ${ }^{5}$.

La situación de partida es de desigualdad (unos ciudadanos bilingües y otros no), y valorar aquello que tiene por efecto crearla, el bilingüismo, en este caso concreto se justifica en que hace posible la cooficialidad, el derecho de los ciudadanos a usar cualquiera de las dos lenguas que son oficiales en la Comunidad Autónoma.

Sólo recordar que a juicio de nuestro TC, como subraya Agirreazkuenaga, el principio de igualdad únicamente resulta vulnerado cuando la diferencia está desprovista de una justificación objetiva y razonable, con lo que no existe una exigencia de tratamiento idéntico para todos los ciudadanos, sino de trato no discriminatorio, no desigual para situaciones iguales pero diferente para las que son distintas ${ }^{6}$. He aquí una muestra, aunque podrían recogerse muchas más, de la hermenéutica que despliega el Alto tribunal acerca del art. $14 \mathrm{CE}$ :

«El principio de igualdad no implica en todos los casos un tratamiento legal igual con abstracción de cualquier elemento diferenciador de relevancia jurídica; pero no lo es menos que este tratamiento legal desigual tiene un límite que consiste en la discriminación, es decir, en el hecho de que la desigualdad esté desprovista de una justificación objetiva y razonable» (STC 5-5-82, fj3 $\left.3^{\circ}\right)^{7}$.

Así pues, podemos extraer varias conclusiones: una que «la "desigualdad" de incluir el conocimiento del euskera en las pruebas de acceso a las plazas de las Administraciones Públicas de Euskadi, viene amparada y recogida por el derecho a la igualdad ante la Ley, además de por el carácter oficial de la lengua vasca» ${ }^{8}$.

Otra, que el límite de la diferencia de tratamiento lo constituye la discriminación, entendiendo que se produce ésta cuando la singularización está desprovista de objetiva justificación, no resulta razonable para la finalidad perseguida o son desproporcionados los efectos producidos.

En este sentido el ejercicio sobre el conocimiento del euskera no quebranta la igualdad de los ciudadanos, en términos de generalidad, ni en orden al acceso a la función pública, derechos fundamentales, en cuanto responde a

\footnotetext{
${ }^{5}$ Además de Cobreros Mendazona, lo advierten Moles i Plaza, R. y Martí i Botella, J., «Notes sobre la doctrina del TS en relació amb el fet multilingüe a l'estat espanyol», Llengua i Dret, n. ${ }^{\circ}$ 9, Barcelona, junio 1987.

${ }^{6}$ AgirReazkuenaga, Iñaki, «La exigencia del euskera en el acceso a la función pública: jurisprudencia y planificación normativa», en Jornadas sobre el régimen jurídico del euskera, en CoBRERos, E., Jornadas sobre el régimen jurídico del euskera, IVAP, Bilbao, 1990, p. 262.

${ }^{7}$ Se reitera en SSTC 22-11-83, de 2 julio 1981, 10 julio de 1981, 10 nov 1981, 21 abril 1982, 3 agosto 1983, 24 enero 1984 etc.

${ }^{8}$ LARRUNBe BiURrun, Kepa, «Nota sobre euskera y ordenanzas municipales» en CoBreros, E., Jornadas sobre el régimen jurídico del euskera, IVAP, Oñati, 1990, p. 402.
} 
exigencias objetivas constitucionalmente protegidas en razón de la cooficialidad de lengua, generadora de aparentes desigualdades, producto del bilingüismo, que no resultan tales en realidad, habida cuenta la existencia de circunstancias de rango fundamental determinantes del especial tratamiento.

\section{La concreta trascendencia que cabe asignar al conocimiento de la lengua cooficial para el acceso a la función pública que sir- ve en la Comunidad Autónoma dotada de cooficialidad: su va- lor de mérito con carácter general y de requisito lingüístico para ciertas plazas}

\section{a) Jurisprudencia constitucional: STC 82/1986, de 26 de junio}

Tres años después de la sentencia relativa a la LOAPA, y con motivo del recurso de inconstitucionalidad contra la Ley 10/1982, de 24 de noviembre, Básica de Normalización del Uso del Euskera, en la STC 82/1986, de 26 de junio el Tribunal Constitucional reitera el aserto de que es deber de toda Administración Pública radicada en una Comunidad Autónoma con régimen de cooficialidad, adaptarse a la situación de bilingüismo, pero añadiendo ahora que esta obligación de resultado cabe alcanzarse con la imposición del deber individual de conocer el idioma propio para determinadas plazas.

Afirma: «nada se opone a que los poderes públicos prescriban en el ámbito de sus respectivas competencias el conocimiento de ambas lenguas para acceder a determinadas plazas de funcionario o que, en general, se considere como mérito, entre otros, como expresamente se prevé, el nivel de conocimiento de las mismas».

Encuentra que es justificación razonable la que ya apreciara con ocasión del examen de constitucionalidad de la LOAPA, esto es «la obligación de garantizar el uso de las lenguas oficiales por los ciudadanos», pero agregando «el deber de proteger y fomentar su conocimiento y utilización», es decir la competencia autonómica de la normalización.

Depués sigue razonando conforme a las exigencias de los arts. 14 y 23 de la Carta magna y para adicionar el siguiente condicionamiento para la validez de esta opción legislativa: que «todo ello ha de hacerse dentro del necesario respeto a lo dispuesto en los arts. 14 y 23 de la CE, y sin que en la aplicación del precepto legal en cuestión se produzca discriminación». O como más adelante dice en lo que atañe al n. ${ }^{\circ} 2$ del art. 14 de la Ley Vasca 10/1982 -el cual reza: «Los poderes públicos determinarán las plazas para las que es preceptivo el conocimiento de ambas lenguas»-, «que la exigencia del bilinguiismo ha de llevarse a cabo con un criterio de razonabilidad y proporcionalidad desde la perspectiva de lo dispuesto en los arts. 23.2, 139.1 y 149.1.1 de la Constitución». 
EL PESO DE LAS LENGUAS COOFICIALES EN EL ACCESO A LA FUNCIÓN PÚBLICA...

En suma, el Tribunal es con base al derecho constitucional de los ciudadanos a usar la lengua oficial propia y la acción de normalización, que justifica la posibilidad legislativa de requerir el conocimiento de lenguas autonómicas para acceder a ciertos puestos de la Administración, pero no con carácter general; con tal dimensión sólo puede reputarse un mérito.

Esto no encuentra oposición en los arts. 14, 23.2, 139.1 y 149.1.1 de la Constitución, que lo que implican no es excluir valorar esta competencia linguiística como mérito o requisito en el acceso a la función pública, sino hacerlo con arbitrariedad, a saber sin razonabilidad ni proporcionalidad, lo que en el presente caso se traduce en exigir el conocimiento con carácter eliminatorio para acceder a los empleos públicos con carácter general.

En el presente caso están justificadas o son razonables las diferencias basadas en la cooficialidad, que guardan proporcionalidad, lo que se traduce en que el ejercicio sobre el conocimiento de la lengua cooficialidad pueda con carácter general fijarse como voluntario para establecer un mérito en orden al acceso a las plazas de la Administración pero no como eliminatorio, como requisito, que sólo puede ocurrir para algunas de ellas?.

\section{b) Jurisprudencia del Tribunal Supremo a partir de 1986}

El Tribunal Supremo a pesar de que a partir de la sentencia de la Sala $3^{\mathrm{a}}$, de 23 septiembre 1986, corrige su jurisprudencia y comienza a hacerse eco de la constitucional ${ }^{10}$, esgrimiendo el art. 5.1 de la Ley Orgánica del Poder Judicial ${ }^{11}$; lo hace remitiéndose a la doctrina del TC de 5 de agosto de 1983 (STS de 13 de octubre de 1987), o aun haciéndolo a la de 1986, poniendo el acento en la parte de aquel pronunciamiento constitucional que se refiere al condicionamiento de que no queden conculcados los artículos 14 y 23 de la Constitución, y concluyendo que sólo sea conforme a Derecho un ejercicio de carácter voluntario y no eliminatorio, cuya calificación máxima no pueda otorgarle un significado determinante y decisiva para obtener la plaza, ...» (STS de 3 de marzo de 1988) ${ }^{12}$.

\footnotetext{
9 Sobre el principio de igualdad Vid. MARTínez TAPIA, R., Igualdad y razonabilidad en la justicia constitucional, Universidad de Almeria, Servicio de Publicaciones, Almería, 2000.

10 Como advierte Cobreros Mendazona, El régimen jurídico de la oficialidad del euskera..., p. 82, aun con posterioridad a esta sentencia seguirá manteniendo su viejo criterio en las SSTS. 19 octubre 1986, 20 octubre 1986, 28 octubre 1986.

${ }^{11}$ El art. 5.1 LOPJ prescribe que todos los Jueces y Tribunales «interpretarán y aplicarán las leyes y los reglamentos según los preceptos y ppios constitucionales, conforme a la interpretación de los mismos que resulte de las resoluciones dictadas por el TC en todo tipo de procesos».

12 LoRenzo De Membiela, Juan B., El acceso y la provisión de puestos de trabajo en la Administración pública, Thomson Aranzadi, Navarra, 2005, p. 59, cita entre las Sentencias pertenecientes a esta fase: SSTS de 23 de septiembre de 1986, de 23 de diciembre de 1986, 3 de marzo de 1987, 4 de marzo de 1987, 16 de diciembre 1987, 25 de enero de 1988, 3 de marzo de 1988, 15 de marzo de 1988 y 21 de marzo de 1988.
} 
En relación con la consideración del manejo de la lengua autonómica como mérito en el acceso a las funciones públicas local y autonómica, que como decimos empieza a aceptar, deja establecido que exista proporcionalidad entre la puntuación otorgada a la lengua vernácula y «el conjunto de la valoración de los demás méritos, de tal modo que aquélla no pueda neutralizar por sí misma a los profesionales» (Sentencia de 23 de diciembre de 1986).

En otras ocasiones (STS de 16 de diciembre de 1987), y ya definitivamente a partir de $1989^{13}$, llegando a día de hoy ${ }^{14}$, el órgano judicial efectúa una exégesis de la jurisprudencia del Máximo intérprete de la Carta magna, por la que decide que no hay obligación de conocer la otra lengua oficial para acceder a la función pública, tal deber es una excepción, que existe por la naturaleza del puesto de trabajo. Como regla el idioma cooficial sólo puede ser valorado como mérito, y como tal en el sentido antes descrito.

Se recalca, que como dijera el Tribunal Constitucional en la Sentencia de 1986 la finalidad de la excepción es la de proveer a la presencia en la Administración de personal de habla vernácula como modo de garantizar el derecho de usarla por parte de los ciudadanos de la respectiva Comunidad.

Por lo que constituye una discriminación en el acceso a la función pública imponer la competencia linguiística para cubrir plazas que no están directamente vinculadas a la utilización por los administrados de las lenguas vernáculas. Lo que obliga a valorar en cada caso las funciones que sean competencia de la plaza a cubrir y el conjunto de funcionarios a los que corresponda un determinado servicio.

Esta doctrina que sostiene el TS, no le ha impedido empero, declarar a la par justificado la exigencia de conocimientos idiomáticos para plazas de atención no ya al ciudadano sino a los empleados públicos, que según se afirma, también gozan del derecho de usar y ser atendidos en la lengua oficial de su elección.

A este respecto es muy elocuente la STS de 20 de noviembre de 1989 que razona como sigue:

«si bien el Tribunal Constitucional tiene declarado que el deber de atender a los ciudadanos de una Comunidad Autónoma con idioma peculiar, tanto en éste como en español, es obligación de la Administración en general y no de todos los funcionarios de la Administración Autonómica, no lo es menos que, como recoge la Sentencia de instancia, con cita de la doctrina del Tribunal Constitucional, "nada se opone a que los poderes públicos prescriban, en el ámbito de sus respectivas competencias, el conocimiento de ambas lenguas para acceder a determinadas plazas", particular este ya recogido por la doctrina de esta Sala, pero matizando que la decisión admi-

\footnotetext{
13 Fecha que señala LoREnZo de Membiela.

${ }^{14}$ Esta doctrina se enuncia expresamente en las SSTS de 16 de abril de 1990, 17 de mayo de 1991 y 8 junio 1991, 15 de diciembre de 1998, 21 octrubre 1999 y 18 de enero de 2000.
} 
EL PESO DE LAS LENGUAS COOFICIALES EN EL ACCESO A LA FUNCIÓN PÚBLICA...

nistrativa relacionada con la mencionada exigencia, determina que la Administración convocante, en este caso la Excma. Diputación Foral de Guipúzcoa, debe justificar la exigencia del conocimiento por esa plaza, y ello, sin duda, sucede en el caso de Autos, por cuanto el acuerdo de convocatoria donde se exige como obligatorio y eliminatorio un ejercicio de conocimiento del euskera, viene precedido de un informe, donde se justifica la necesidad de tal conocimiento, habida cuenta que el cometido fundamental de las tareas a realizar por el citado técnico está relacionado con la solución de problemas y reclamaciones de los empleados en cuestiones de salarios, seguros sociales, elaboración de calendarios laborales, elecciones sindicales, notas informativas de carácter general, normas de obligado cumplimiento, ayudas de estudios, guarderías, etc., aclarando que esta labor está basada en un contrato permanente, tanto directo como telefónico, con todos los empleados de la provincia y con entes públicos y Ayuntamientos de la misma, los cuales, obviamente, tienen perfecto derecho a expresarse en cualquiera de las dos lenguas oficiales en la Comunidad Autónoma y a ser informados en ella; es decir, del informe mencionado, donde se describe con meticulosidad el contenido de las funciones del puesto de trabajo administrativo a cubrir, se deduce la necesidad del mencionado conocimiento idiomático, lo que supone la corrección de la decisión tomada en orden a la convocatoria y la procedencia de la desestimación del recurso, con la confirmación de la Sentencia de instancia, habida cuenta que, si bien el conocimiento del idioma de la Comunidad Autónoma no es exigible a todos los funcionarios de una determinada sección o negociado, sin que ello es necesario se dé en los principales responsables de ellos y en un determinado porcentaje del resto de funcionarios a su servicio».

Gran parte de la doctrina interpreta en este mismo sentido la sentencia del Tribunal Constitucional ${ }^{15}$.

El sistema hasta aquí aludido se ha venido a llamar de «mínimos», de manera que no se reclama a todos lo funcionarios saber las dos lenguas oficiales, sino sólo a una parte, a aquéllos que hayan de desarrollar sus funciones en puestos para los cuales sea inexcusable su manejo. Según se entienda la inexcusabilidad, el grupo será más o menos amplio. Se trata de garantizar un mínimo de personal capaz para atender al ciudadano, no que todos los funcionarios tengan conocimiento de la lengua propia ${ }^{16}$. Este sistema consolida una situación de mínimos, no garantiza un conocimiento por todos los que van a ser funcionarios de la lengua propia.

Pero también hay autores en contra de esta exigencia aunque sea de mínimos, declarando que el idioma no constituye por sí un elemento de impor-

\footnotetext{
${ }^{15}$ PRIETo DE PEDRo, J., «El conocimiento de las lenguas propias de las Comunidades Autónomas y extranjeras como requisito de capacidad de los funcionarios de la Administración del Estado», Llengua $i$ Dret, n. ${ }^{\circ}$ 12, Barcelona, julio 1989, p. 151; PRIETO DE PEDRO, J., «Libertades lingǘsticas, doble oficialidad e igualdad en la jurisprudencia», Llengua i Dret, n. ${ }^{\circ} 14$, Barcelona, 1990, pp. 24-25; BAÑo LEón, J. M., «El ejercicio del pluralismo lingüístico en la Administración Pública», Revista Española de Derecho Administrativo, 1987, pp. 239 y 240.

${ }^{16}$ Información obtenida en VERNET I LlOBET, J., «La regulació del plurilingüisme a l'Administració espanyola (1977-1990)», Llengua i Dret 18, Barcelona, 1992, p. 143.
} 
tancia tan relevante como para afectar la capacidad del opositor; que sea una circunstancia tan esencial como para excluir a ciudadanos a concurrir a una plaza en la Administración en ejercicio de su derecho constitucional al trabajo contenido en el art. 35.1CE; y aun cuando el fin último sea preservar una lengua cooficial y constitucional ${ }^{17}$.

Por último, otro sector doctrinal defiende que además del argumento empleado por el Tribunal Constitucional y de aquél primer sector -el derecho al uso de la lengua oficial que elijan los ciudadanos ante la Administración Pública y derecho a ser atendidos- existen otros para justificar la posibilidad de ordenar el conocimiento de la lengua cooficial como condición general de acceso a las actividades públicas, con la única condición de que el nivel pedido guarde proporción con el conocimiento que requiere la función pública.

Este sistema sí garantizaría que todos los funcionarios sean competentes lingüísticamente, al tiempo que respetaría la proporcionalidad, puesto que aunque a todo hombre se le exigiría un grado general y mínimo de conocimientos de la lengua propia, a su entrada, también permite reivindicar un segundo nivel de conocimientos lingüísticos dependiente de la función concreta a desempeñar, del lugar de trabajo ${ }^{18}$.

La posibilidad para la Comunidad Autónoma y el Estado de reclamarlo con carácter general radica en que, aunque este derecho de opción lingüística del ciudadano pudiera satisfacerse con un grupo reducido de servidores bilingües, otras razones justifican la opción por la no segregación: razones de eficacia ${ }^{19}$, de normalización ${ }^{20}$, de la relación de subordinación especial a que está sujeto el funcionario ${ }^{21}$, y de propiedad de la lengua ${ }^{22}$.

Habiendo esbozado los modelos posibles, si atendemos a la legislación de normalización y de función pública del País $\mathrm{Vasco}^{23}$, Valencia ${ }^{24}$, y Na-

\footnotetext{
17 Lorenzo de Membiela, Juan B., op. cit., p. 61.

18 Milian i Massana, A., «La ordenación estatutaria de las lenguas españolas distintas del castellano», Revista vasca de Administración Pública, 1983, pp. 243-245.

19 También utiliza este argumentos Cobreros Mendazona, E., «Cooficialidad lingüística...», p. 474, Milian i Massana, A., «La Regulación constitucional del multilingüismo», Revista Española de Derecho Constitucional, n. ${ }^{\circ}$ 10, 1984; VERnET I Llobet, J., op. cit., p. 94.

${ }^{20}$ Agirreazkuenaga Zigorraga, I., «El euskera discrimina al castellano a juicio del TS», $R V A P, \mathbf{n}^{\circ}$ 9, 1984, p. 250; Milian i Massana, A., «La ordenación estatutaria de las lenguas...», 1983.

21 Vernet i Llobet, J., op. cit., p. 113.

22 Vernet i Llobet, J., op. cit, p. 141.

${ }^{23}$ Ley Básica de Normalización del uso del euskera: art. 14; arts. 97-99 de la Ley 6/1989, de 6 de julio, de la Función Pública Vasca, y su normativa de desarrollo. Para un análisis de ésta vid. BAZAKo, Peru, «La Ley de la Función Pública Vasca: desarrollo normativo. Sectores sin planificación: sanitario y ertzaintza», Revista Vasca de Administración pública, INAP, 1996 y CoBRERos Mendazona, E.,: La política de normalización...1990, pp. 272,273; ERKOREKA GERVASIO, Josu Iñaki, «El Euskera en la Administración Pública Vasca; origen, situación actual y perspectivas», Rev. Int. Estud. Vascos, 43, 2, 1998, 425-439, pp. 436 y ss.

24 El Artículo 30 Ley 4/1983, de 23 de noviembre, de uso y enseñanza del valenciano en el apartado segundo dispone que «En las bases de convocatoria para acceso al desempeño de cargos, empleos y
} 
varra ${ }^{25}$ comprobamos que exigen el conocimiento de la lengua cooficial solamente para determinados puestos, considerándose un mérito para los restantes. Por el contrario, la de Cataluña ${ }^{26}$, Baleares ${ }^{27}$ y Galicia ${ }^{28}$ lo imponen para acceder a la función pública en general.

\section{El conocimiento de la lengua autonómica como requisito para el acceso a la función pública: requisito general versus requisi- tos para ciertas plazas}

a) Jurisprudencia constitucional: STC 46/1991, de 28 de febrero

A pesar de que en Cataluña la Ley 7/1983, de 18 de abril, de Normalización Linguíística en Cataluña nada estableció acerca de que el conocimiento del catalán fuera mérito o requisito en el acceso a la función pública, y sólo se pronunciaba en el art. 18 sobre los profesores — «De acuerdo con las exi-

funciones públicas, por la Generalitat Valenciana y las Corporaciones Locales, en el ámbito de sus respectivas competencias, se valorará el conocimiento del valenciano a fin de que puedan realizarse aquellas funciones públicas de acuerdo con los principios de uso del valenciano, previsto en la presente Ley». Y en el tercero que «Los poderes públicos valencianos, a los efectos del apartado anterior, señalarán las plazas para las que sea preceptivo el conocimiento del valenciano».

25 Para la zona vascófona el art. 15 de la Ley Foral de 15 de diciembre de 1986, del vascuence, contempla que necesariamente se habrán de especificar las plazas para las que será prescriptivo el conocimiento del vascuence, considerándose mérito cualificado para las demás. Para la zona mixta el art. 17 de la Ley dice que podrán especificarse plazas para las que el conocimiento sea preceptivo así como valorarlo como mérito.

${ }^{26}$ Vid. art. 42 del Decreto Legislativo 1/1997, de 31 de octubre, por el que se aprueba el Texto Refundido de las disposiciones Legales Vigentes en Materia de Función Pública. Decretos del Consejo Ejecutivo de 13 de marzo y 4 de agosto de 1987, sobre uso de lenguas oficiales por la Administración de la Generalidad de Cataluña.

${ }^{27}$ La Ley 2/1989, de 22 de febrero, de la Función pública de la CA de las Islas Baleares, según redacción de la Ley 1/1996, de 23 de abril en la sección relativa a la selección del personal el art. 45 dice: «La selección del personal al servicio de la Administración autonómica, sea funcionario, sea laboral, de acuerdo con la oferta pública de empleo que se haya realizado, se efectuará con criterios de objetividad en aplicación de los principios de igualdad, mérito y capacidad de los aspirantes y previa convocatoria pública.

En las pruebas selectivas que se realicen para el acceso a las plazas de la Administración en el ámbito territorial de las Islas Baleares, se habrá de acreditar el conocimiento de la lengua propia de la Comunidad Autónoma en su expresión oral y/o escrita, respetando plenamente el principio de proporcionalidad a nivel de exigencia de un determinado conocimiento, que deberá estar relacionado, en cualquier caso, con las plazas o funciones de que se trate».

Para conocer la situación precedente vid. MiLIAN i MASSANA, Antoni, «Planificación lingüística en las Administraciones de las CCAA con doble oficialidad lingüística», Revista Vasca de Administración Pública, n. ${ }^{\circ}$ 44-II, 1996, pp.118-119.

${ }^{28}$ El art. 11 de la Ley 3/1983, de normalización Lingüística de Galicia previene: «1. A fin de hacer efectivos los derechos reconocidos en el presente título, los poderes autonómicos promoverán la progresiva capacitación en el uso del gallego del personal afecto a la Administración Pública y a las empresas de carácter publico en Galicia. 2. En las pruebas selectivas que se realicen para el acceso a las plazas de la Administracion autónoma y local se considerará, entre otros meritos, el grado de conocimiento de las lenguas oficiales, que se ponderará para cada nivel profesional». 
gencias de su labor docente, los profesores deben conocer las dos lenguas oficiales»— sí lo hizo la Ley del Parlamento de Cataluña 17/1985, de 23 de julio de la Función Pública de la Administración de la Generalidad.

La norma se ocupó del tema en el art. 34 previniendo que «De acuerdo con los principios enunciados por el art. 103.1 de la Constitución, la Administración de la Generalitat selecciona todo su personal con criterios de objetividad, en función de los principios de igualdad, mérito y capacidad de los aspirantes, y mediante convocatoria pública. En el proceso de selección, se ha de acreditar el conocimiento de la lengua catalana, tanto en la expresión oral como en la escrita».

La misma idea directriz es seguida hoy por la vigente Ley 1/1998 de 7 de enero, de Política Lingüística en Cataluña que preceptúa en el apartado 3..$^{\circ}$ del art. 11 que «En el proceso de selección para acceder a plazas de personal de la Administración de la Generalidad, la Administración local y la Administración y Servicios de las Universidades, incluido el personal laboral, debe acreditarse el conocimiento de la lengua catalana, tanto en la expresión oral como en la escrita, en el grado adecuado a las funciones propias de las plazas de que se trate, en los términos establecidos en la función pública» ${ }^{29}$.

Al preguntarnos por la compatibilidad de este sistema con el bloque de la constitucionalidad, primero examinaremos si lo es con la legislación básica del Estado, concretamente con el art. 19 de la Ley estatal 30/1984, de medidas urgentes para la reforma de la función pública que el art. 1 de la Ley 23/1988, de modificación de la LMRFP, declara norma básica, y que dispone que $« N^{\circ}{ }^{\circ} 1$ los procedimientos de selección "cuidarán especialmente la conexión entre el tipo de pruebas a superar y la adecuación a los puestos de trabajo que se hayan de desempeñar". Y más en particular para el caso que nos ocupa, que en las convocatorias para el acceso a la función pública, "las Administraciones públicas, en el respectivo ámbito de sus competencias, deberán prever la selección de funcionarios debidamente capacitados para cubrir los puestos de trabajo en las Comunidades Autónomas que gocen de dos lenguas oficiales"».

Para una parte importante de la doctrina el redactando del art. 19 permite exigir el conocimiento de la lengua propia para el acceso a la función pública $^{30}$. Cosa distinta es que quepa inferir que deje pedirlo de modo generalizado, y no exclusivamente para ciertos puestos.

No obstante, con independencia de su contenido, se plantea una cuestión previa que es la de si realmente la norma tiene la condición de básica, y vincula por tanto a la Comunidad autónoma.

\footnotetext{
${ }^{29}$ La Generalidad de Cataluña ha procedido a desarrollar esta previsión legal a través del Decreto 161/ 2002, de 11 de junio, sobre acreditación del conocimiento del catalán y el aranés en los procesos de selección de personal y de provisión de puestos de trabajo de las administraciones públicas de Cataluña.

30 BAÑo LEÓN, op. cit., 79; LÓPEZ BASAGUREN; VERNET I LlOBET, J., La regulació del plurilingüisme a l'Administració... 1992, p. 91.
} 
EL PESO DE LAS LENGUAS COOFICIALES EN EL ACCESO A LA FUNCIÓN PÚBLICA...

Pues si de una parte al legislador estatal corresponde por virtud del art. 149.1.1 a regular la igualdad en las condiciones básicas del ejercicio de los derechos y libertades, y del art. 149.1.18 las normas básicas sobre estatuto de la función pública, que de acuerdo con las SSTC 99/ $1987 \mathrm{FJ}^{\circ}$ y $85 / 1983 \mathrm{FJ} 1^{\circ}$ incluye la normativa relativa a la adquisición de la condición de funcionario; no podemos dejar de ver que con ello el legislador estatal «concreta el mandato del art. 3.2 CE en relación con el derecho de acceso a la función pública» ${ }^{31}$.

Pero no solo eso, sino también que no se respetaría la idea manifestada por el TC en la STC 82/86 de que enunciadas las consecuencias inmediatas de la cooficialidad, lo que es su concreción sólo a cada Administración incumbe.

Además, el Alto tribunal en la sentencia que acto seguido comentaremos, STC 46/1991, no habla para nada de que el legislador autonómico al ordenar esta materia esté sujeto por la legislación básica estatal, y que la tenga que respetar. Por el contrario, para el caso de la regulación del idioma en el sistema educativo, sí que explícitamente se referirá al carácter básico de la normativa estatal (STC 337/1994).

Contra el inciso final del citado artículo 34 se interpuso recurso de inconstitucionalidad por el Gobierno de la nación ${ }^{32}$, resuelto por la STC 46/1991, de 28 de febrero, a favor de su conformidad constitucional.

El Supremo intérprete del Texto fundamental en el Fundamento Jurídico 3. ${ }^{\circ}$, acepta que exigir el conocimiento del catalán sea parte integrante de los principios constitucionales de mérito y capacidad, que rigen el acceso a la función pública de acuerdo con el art. 103.3 CE: «El principio de mérito y capacidad supone la carga para quien quiera acceder a una determinada función pública de acreditar las capacidades, conocimientos e idoneidad exigibles para la función a la que aspira. Por lo que la exigencia del conocimiento del idioma que es oficial en el territorio donde actúa la Administración a la que se aspira a servir es perfectamente incluible dentro de los méritos y capacidades requeridas».

Pero además, encuentra «razonable» la fórmula legal de fijarlo como «requisito general de capacidad» [...] «...resulta constitucionalmente lícito exigir, en todo caso, un cierto nivel de conocimiento de la lengua catalana...», condicionándolo a que sea «variable en su nivel de exigencia».

Y lo enjuicia razonable por varios motivos: «En primer lugar, debemos mencionar el carácter del catalán como lengua de la Administración de la Generalidad junto con el castellano, ambas de uso preceptivo (art. 5 LNL);

\footnotetext{
31 BAÑo LEÓN, op. cit., p. 236

${ }^{32}$ Recurso de inconstitucionalidad de 6 de noviembre de 1985.
} 
que son válidas y eficaces las actuaciones administrativas hechas en catalán (art. 7.1 LNL); y que los particulares gozan del derecho a usar el catalán en sus relaciones con la Administración (art. 8 LNL y STC82/86, FJ $3^{\circ}$ ). Además, se trata de un requisito justificado y equitativo también en función de la propia eficacia de la Administración autónoma (art. 103.1 CE)..., resulta imprescindible para que el funcionario pueda ejercer adecuadamente su trabajo en la Administración autonómica dado el carácter cooficial del idioma catalán en Cataluña (art. 3.2 CE y art. 3.2 EAC) y dada también la extensión del uso del catalán en todo el territorio de la Comunidad Autónoma».

En nuestra opinión, los términos en que se expresa el TC para exponer sus conclusiones, así como las razones en que se apoya para alcanzarlas, nos hacen ver que declara constitucional hacer la competencia lingüística requisito general de acceso a la función pública ${ }^{33}$.

A nuestro juicio, el Tribunal Constitucional, al igual que en la STC 82/ 86, continúa adoptando como parámetros para valorar la razonabilidad de la medida el derecho a usar de los ciudadanos y el estatuto oficial de la lengua regional, y sin embargo decide de un modo distinto: la validez de reclamar un conocimiento del idioma con carácter general para acceder a la función pública.

El único elemento diferencial que parece explicar tal viraje doctrinal, que juzga razonable la imposición del legislador autonómico, nos parece que es que la Alta instancia toma además en consideración el uso extendido del catalán en todo el territorio de la Comunidad Autónoma, o lo que es lo mismo la situación sociolingüística.

Lo anterior ha servido a algún autor para escribir que la Alta jurisdicción estaría apreciando la lengua, el catalán, como derecho de una comunidad linguística, y su necesaria protección, el derecho a la lengua de una colectividad $^{34}$.

Lo cierto es que en esta resolución más que a la acción de normalización, a la que sí alude en la STC 82/86, el TC recurre al estatus de la oficialidad para justificar la solución que alcanza.

En este sentido, argumentos que figuran entre las alegaciones del Abogado de la Generalidad — que se trata de una «medida de normalización linguíística que tiene un efecto compensatorio» con fundamento en los arts. 3.3 de la CE y 3.3 del EAC—, y del Abogado del Parlamento de Cataluña —que se había de tener en cuenta el especial esfuerzo que se ha de realizar para superar la etapa de opresión de la lengua catalana, por lo que los poderes públicos, de acuerdo con el art. 9.2 CE, deben ser beligerantes en la promoción

\footnotetext{
${ }^{33}$ Han determinado lo mismo Triadú I Vila-AbadAl, Joaquim, «Perspectiva constitucional i Carta Europea de les Llengües regionals o minoritàries», Llengua i Dret, n. ${ }^{\circ}$ 37, Barcelona, septiembre 2002, p. 131.

34 Vernet i Llobet, J., op. cit., p. 112, Corretja i Torrens, M., 1991, pp. 80, 82, 83.
} 
EL PESO DE LAS LENGUAS COOFICIALES EN EL ACCESO A LA FUNCIÓN PÚBLICA...

de las condiciones sociales para hacer reales los derechos lingüísticos del pueblo catalán-, no encuentra reflejo en la resolución, a diferencia de lo sí sucederá en la STC 337/1994, de 23 de diciembre, relativa a la educación.

A nuestro parecer, tampoco utiliza el Alto Tribunal (ni en este fundamento número 3 ni en el número $2^{35}$ - donde el TC examina la constitucionalidad del precepto de la Ley de Función pública a la luz del art. 139.1 CE-) el atributo de «lengua propia» que asigna al catalán el EAC y la Ley de Normalización, para otorgar a este idioma un significado distinto al que supone su carácter de lengua oficial por virtud de la CE y el EA.

Con lo que en esta resolución no asume la Corte constitucional la tesis del sector que sostiene que la expresión tiene la consecuencia jurídica de hacer el catalán la lengua de uso prioritario o principal de la Administración Pública en Cataluña ${ }^{36}$.

El TC admitiendo la constitucionalidad de la exigencia general del conocimiento del idioma vernáculo para el acceso a la función pública, no desemboca más que en una exigencia igual a la de la otra lengua oficial, el castellano.

Aunque pudieramos objetar que el TC se contradice, pues inicialmente había dicho que las lenguas son oficiales con independencia de su peso social (STC 82/86), también hay que recordar que el sentido de la remisión del art. 3.2 CE al Estatuto y el legislador autonómico es el de adaptar las consecuencias de la oficialidad a la realidad social de la correspondiente lengua en su Comunidad Autónoma.

Aunque bajo nuestro punto de vista la Alta instancia modifica la doctrina que sostuviera en las SSTC 76/83 y 82/86, pues defiende ahora la conformidad constitucional de un deber individual de conocimiento del catalán para todos los aspirantes a funcionarios de la Administración autonómica y local (Administraciones a las que es aplicable aquella Ley), no podemos dejar de ver que sigue condicionando el requerimiento al respeto de los artículos 14 y 23.2 del Texto fundamental, si bien en orden a prevenir que el nivel

\footnotetext{
${ }^{35}$ En relación con la presunta desigualdad que originaria el precepto impugnado en los derechos y obligaciones reconocidos a españoles en cualquier parte del territorio nacional (art. 139.1 C.E.) al introducir una exigencia de conocimiento lingüístico para acceder a la función pública de la Administración de la Generalidad de Cataluña que no se establece para el acceso a otras Administraciones, debemos partir del reconocimiento, al amparo de la remisión que efectúa el art. 3.2 C.E., del idioma catalán como lengua oficial en Cataluña (art. 3.2 E.A.C.). Se establece, así, un régimen de cooficialidad lingüística que rige en el territorio de la Comunidad Autónoma de Cataluña y del que, entre otras consecuencias, se deriva que el catalán y el castellano deben ser usados preceptivamente por la Administración en la forma determinada por la Ley (art. 5.2 Ley del Parlamento de Cataluña 7/1983, de 18 de abril, de Normalización Lingüística) y que el catalán sea lengua propia de la Administración territorial catalana (art. 5.1 Ley 7/1983, en relación con el art. 3.1 E.A.C.).

36 VERnET i Llobet, J., «La valoració dels conisements de llengua catalana en l'accés a la funció pública local», Llengua i Dret, n. ${ }^{\circ} 17,1992$, pp. 95 y 110.
} 
concreto de competencia lingüística que se reclame sea proporcionado al tipo y nivel de la función o puesto a desempeñar ${ }^{37}$.

En efecto, el Fundamento Jurídico $4 .^{\circ}$ de la sentencia postula que «Cuestión distinta [...] es la de la proporcionalidad de esa exigencia, en función del tipo y nivel de la función o puesto a desempeñar, que viene impuesta por el art. 23.2 CE, pues sería contrario al derecho a la igualdad en el acceso a la función pública exigir un nivel de conocimiento del catalán sin relación alguna con la capacidad requerida para desempeñar la función de que se trate. Ciertamente una aplicación desproporcionada del precepto legal podría llevar a resultados discriminatorios, contrarios tanto al art. 14 como al 23.2 CE, pero ello no resulta directamente del precepto impugnado, que entiendo en sus propios términos, no tiene nada de objetable desde el punto de vista constitucional».

\section{b) Jurisprudencia del TS: mantenimiento de la línea iniciada en el año 1986 y definitivamente asentada en el año 1989}

El Tribunal Supremo no es de nuestro parecer, y a su juicio la resolución estudiada no presenta un viraje de sentido en la jurisprudencia constitucional sino que muy al contrario resulta confirmatoria de la doctrina presente en la STC de 1986.

Lo afirma profusamente: SSTS 16 de abril de 1990, 8 de julio de 1994, 18 de abril de 1995, 19 de febrero, 26 de marzo y 22 de julio de 1996 y 20 de marzo de 1998, 13 de noviembre de1998, 6 de julio de 1999, 18 de enero de 2000,9 de octubre 2000 .

Limitándonos a los dos primeros puntos en que consiste tal doctrina, dice que «el principio general sigue siendo el que pueda valorarse como mérito no eliminatorio el conocimiento de las lenguas españolas diferentes del castellano»y, «que para concretas y determinadas plazas, los poderes públicos competentes puedan darle el carácter de eliminatorio a la prueba de conocimiento». Otra cosa constituiría discriminación.

Tomaremos como ejemplo la STS 13 de noviembre de 1999, que previene: «Esta doctrina jurisprudencial, en la que se tuvo especialmente en cuanta la sentencia del Tribunal Constitucional de 26 de junio de 1986, que afirmó la constitucionalidad de la Ley Vasca 10/1982, en la que se establecía que los poderes públicos determinarían las plazas para las que sería preceptivo el conocimiento del castellano y el euskera, ha sido ampliada por la sentencia del propio Tribunal Constitucional de 28 de febrero de 1991, según la cual no es inconstitucional el inciso final del artículo 34 de la Ley del Parlamento de Cataluña 17/1985, de 23 de julio, de la Función Pública de la Adminis-

37 Corretua i Torrens, M., op. cit., 1991, p. 79. 
EL PESO DE LAS LENGUAS COOFICIALES EN EL ACCESO A LA FUNCIÓN PÚBLICA...

tración de la Generalidad, que establece, en referencia al personal al servicio de la misma, que en el proceso de selección deberá acreditarse el conocimiento de la lengua catalana en su expresión oral y escrita. Entiende la sentencia que el propio principio de mérito y capacidad para el acceso a la función pública (artículo 103.3. de la Constitución) supone la carga para quien quiera acceder a ella de acreditar las capacidades, conocimientos e idoneidad exigibles para la función a la que aspira, por lo que la exigencia del conocimiento del idioma que es oficial en el territorio donde actúa la Administración a la que aspira a servir es perfectamente incluible dentro de los méritos y capacidades requeridas. Dice la sentencia, sin embargo, que cuestión distinta es la proporcionalidad de esa exigencia, en función del tipo o nivel de la función o puesto a desempeñar, que viene impuesta por el artículo 23.2 de la Constitución, pues sería contrario al derecho de igualdad en el acceso a la función pública exigir un nivel de conocimiento del idioma cooficial de la Comunidad Autónoma que no guarde relación alguna con la capacidad requerida para desempeñar la función de que se trate».

El proceder del Tribunal Supremo ha sido objeto de criticas arguyendo el desconocimiento de la doctrina del constitucional, así como la falta de fundamento de limitar la exigencia del conocimiento del idioma regional para los puestos ocupados por funcionarios que se relacionan con los particulares y no para los otros que realizan tareas internas, cuando la Administración puede funcionar válidamente en ambas lenguas como consecuencia de la doble oficialidad $^{38}$.

La Sección de Uso Oficial de la Lengua Catalana de la Dirección General de Política Lingüística de la Consejería de Cultura de la Generalidad de Cataluña, al hilo de la Sentencia del Tribunal Superior de Justicia de Cataluña de 22 de diciembre de 2002 - que entiende desproporcionada la inclusión de una prueba eliminatoria de lectura en catalán para acceder a la plaza de albañil en el Ayuntamiento de Olot, dado el carácter manual y la ausencia de relación con los administrados que conlleva el desarrollo de las funciones de este puesto de trabajo- remite una nota al Ayuntamiento de Olot en la que le advierte que la S. del TSJ de Cataluña no puede prevalecer ni constituir jurisprudencia delante de la sentencia del TC 46/91, de 28 de febrero ${ }^{39}$.

Con todo, parece que la controversia apuntada queda saldada favorablemente para el Tribunal Supremo pues una reciente sentencia del Tribunal Constitucional, que explícitamente se apoya en la STC 46/91, de 28 de febrero, deja entrever que no es conforme con el art. 23 CE la exigencia generalizada de requisitos linguiísticos para el acceso a la función pública, que para ciertos puestos la misma no encontrará justificación constitucional.

\footnotetext{
38 Vernet i Llobet, J. y Pou i Pujolràs, A., «Tribunal Suprem i Direcció General dels Registres», Lengua i Dret, n. ${ }^{\circ}$ 34, 2000, p. 399.

39 Informa De CARreras, Francesc, y Domingo Domingo, José, «La aplicación de la Ley catalana de política lingüística: su control judicial», en Teoría y Realidad Constitucional, $\mathbf{n} .^{\circ}{ }^{12-13}, 2^{\circ}$ semestre 2003-1er semestre 2004, UNED, p. 82.
} 


\section{c) La última Jurisprudencia constitucional: STC 10-10-2005, de 15 de noviembre}

Se trata de la STC 10-10-2005, de 15 de noviembre ${ }^{40}$, que resuelve el conflicto positivo de competencia promovido por el Gobierno de la Nación frente al apartado 5 de la sección primera del capítulo VI del título II (De las plantillas y relaciones de puestos de trabajo), y al capítulo XIII del título III (retribuciones), en relación con el anexo IV, del Acuerdo con las organizaciones sindicales sobre modernización en la prestación del servicio público de la Justicia y su repercusión en las condiciones de trabajo del personal al servicio de la Administración de Justicia, aprobado por el Decreto del Gobierno Vasco 63/1998, de 31 de marzo.

En la sentencia se pone de manifiesto que la Ley Orgánica 19/2003, de 23 de diciembre - que ha modificado con considerable amplitud la Ley Orgánica del Poder Judicial - ha dado nueva redacción al Libro VI que regula los cuerpos de funcionarios al servicio de la Administración de Justicia y otro personal. Aun no habiendo exigido el conocimiento de la lengua regional por parte de estos funcionarios, ha ponderado que dicha lengua es también oficial en el territorio de ciertas Comunidades Autónomas y, ha previsto que su conocimiento sea tenido en cuenta en la configuración de las relaciones de puestos de trabajo y en los concursos de traslado, en «ejercicio de la competencia estatal regulada en el art. 149.1, número 5 y 6 de la $C E »$ dice la sentencia (fundamento jurídico 10).

Así el art.521 LOPJ contiene una regulación amplia sobre «las relaciones de puestos de trabajo» y en el apartado $4^{\circ}$ al referirse a los requisitos que «podrán contener» cita el «Conocimiento oral y escrito de la lengua oficial propia en aquellas comunidades autónomas que la tengan reconocida como tal».

Y por su parte el Artículo 530 en relación a la provisión de puestos de trabajo establece que «En las convocatorias para puestos de trabajo de las comunidades autónomas con competencias asumidas cuya lengua propia tenga carácter oficial, se valorará como mérito el conocimiento oral y escrito de la misma». Si bien añade inmediatamente que «En determinados puestos, podrá considerarse requisito exigible para el acceso a los mismos, cuando de la naturaleza de las funciones a desempeñar se derive dicha exigencia y así se establezca en las relaciones de puestos de trabajo».

Sobre ambos preceptos y sobre los dos incisos del último argumenta el TC en el fundamento jurídico 10 de la sentencia que glosamos que:

«hay que recordar que en punto a la adecuación de la exigencia del conocimiento de la lengua autonómica cooficial para el desempeño de puestos de trabajo por los fun-

${ }^{40}$ BOE 273/2005, de 15 noviembre 2005 . 
EL PESO DE LAS LENGUAS COOFICIALES EN EL ACCESO A LA FUNCIÓN PÚBLICA...

cionarios al servicio de la Administración de Justicia,..., la cuestión esencial a valorar es "la de la proporcionalidad de esa exigencia, en función del tipo y nivel de la función o puesto a desempeñar, que viene impuesta por el art. 23.2 CE, pues sería contrario al derecho a la igualdad en el acceso a la función pública, exigir un nivel de conocimiento del catalán sin relación alguna con la capacidad requerida para desempeñar la función de que se trate. Ciertamente una aplicación desproporcionada del precepto legal podría llevar a resultados discriminatorios, contrarios tanto al art. 14 como al art. 23.2CE... Por consiguiente, en tanto que en las concretas convocatorias de los concursos u oposiciones de acceso a los cuerpos y escalas o plazas de la función pública de la Generalidad no se utilice la_exigencia de conocimiento del catalán de manera irrazonable y desproporcionada impidiendo el acceso a su función pública de determinados ciudadanos españoles, no se vulnerará la igualdad reconocida por el art. 23.2CE (STC 46/1991, de 28 de febrero, fj4)"».

Este criterio, que en la Sentencia reproducida consideramos aplicable a la Administración Pública de la Generalidad de Cataluña, es, asimismo, predicable de la Administración de Justicia, por estar en cuestión en este punto respecto de ambas Administraciones los mismos principios constitucionales.

Pues bien, es obvio que los reproducidos preceptos estatales relativos al conocimiento de la lengua autonómica cooficial guardan la proporcionalidad exigida, pues el art. 530 LOPJ, en conexión con el art. 521 de la misma Ley, configura los conocimientos de la lengua cooficial como «mérito», que puede operar con carácter general, y ya más concretamente para determinados puestos de trabajo como «requisito exigible», si bien, en cuanto a este último extremo, ello sólo será así «cuando de la naturaleza de las funciones a desempeñar se derive dicha exigencia y así se establezca en las relaciones de trabajo».

Por tanto, puesto que según estos preceptos resulta exigible la ponderación en cada caso de las relaciones de puestos de trabajo y, dentro de ellas, de las características específicas de los puestos en que se concrete la exigencia de conocimiento del euskera, queda suficientemente salvaguardado el principio de proporcionalidad y nada cabe oponer desde el punto de vista del orden constitucional de distribución de competencias a que la previsión contenida en el Acuerdo aprobado por Decreto del Gobierno Vasco 63/1998, de 31 de marzo, haya establecido que las relaciones de puestos correspondientes a la CA del País Vasco puedan incluir el requisito del «conocimiento del euskera en determinados puestos», pues esta previsión se acomoda a lo regulado en la LOPJ.

A nuestro juicio el Máximo intérprete de la Carta magna viene a avalar la teoría del Tribunal Supremo de que la exigencia general de conocimientos linguíísticos para el ingreso o la provisión de puestos de trabajo en la función pública no es adecuada por desproporcionada, reclamando este principio de proporcionalidad estar a las características de cada puesto.

Aunque el Tribunal Constitucional cita la Sentencia 46/1991, de 28 de febrero, de la misma sólo selecciona aquél fragmento relativo a que la exi- 
gencia de competencia lingüística en lengua cooficial debe ser en un nivel ajustado al puesto a desempeñar, omitiendo el otro en que respaldaba la imposición del requisito lingüístico con carácter general. Ese fragmento y el énfasis que ahora hace la resolución en que el principio de proporcionalidad impone ineludiblemente que el requisito linguiístico sea necesario a la vista del puesto a desempeñar, nos conducen a pensar que lo que realmente hace el órgano constitucional es rectificar su anterior doctrina en este sentido, refrendando así la doctrina sentada por el Tribunal Supremo. Y esta es la tesis que en el presente estudio sostenemos.

No obstante, resulta conveniente observar que uno de los Magistrados empero emite un voto particular por no estar de acuerdo con que la disposición legislativa y por ende el Acuerdo impugnado, respeten el principio de proporcionalidad. Dice textualmente como sigue

«Sin embargo, en lo que se refiere a la "ponderación en cada caso de las relaciones de puestos de trabajo", no acierto a adivinar qué se quiera significar con tal expresión. Por su parte, la necesidad de «ponderación de las características específicas de los puestos en que se concrete la exigencia», que es, en definitiva, la única previsión sustantiva contenida en el art. 530 LOPJ, es tan absolutamente indefinida, vacía de contenido y ayuna de cualquier parámetro que tomar en consideración a la hora de efectuar la ponderación que se demanda, que no creo que garantice ni salvaguarde, en modo alguno y mucho menos suficientemente, el principio de proporcionalidad que constituye nuestro canon de constitucionalidad, de suerte que podría llevar a resultados discriminatorios, contrarios tanto al art. 14 como al art. $23 \mathrm{CE}$ de los que es necesario advertir. La inexistencia de indicadores que precisen cuándo, de la naturaleza de las funciones a desempeñar, será razonable o proporcionado derivar la exigencia de conocimiento de las lenguas cooficiales para acceder al desempeño de tales puestos de trabajo, va a abrir indeseables espacios a la más absoluta discrecionalidad, cuando no a la arbitrariedad, sustentada en razones de pura oportunidad política, lo que constituirá una fuente de conflictos jurisdiccionales.

Considero, en definitiva, que este precepto estatal relativo al conocimiento de la lengua autonómica cooficial (art. 530 LOPJ, en su segundo inciso), no salvaguarda el principio de proporcionalidad debida, lo que puede llevar a resultados discriminatorios, contrarios tanto al art. 14 como al art. 23 CE. Por esta razón, la previsión contenida en el Acuerdo aprobado por Decreto del Gobierno Vasco 63/1998, de 31 de marzo, de que las relaciones de puestos de trabajo correspondientes a la Comunidad Autónoma del País Vasco puedan incluir el requisito del "conocimiento del euskera en determinados puestos", aunque se acomoda a lo regulado en la vigente LOPJ, tampoco puede, en consecuencia, salvaguardarlo».

Esta crítica vertida por el Magistrado D. Roberto García-Calvo y Montiel nos hace reparar sobre el hecho de que en este caso no realiza el Tribunal Constitucional una sentencia interpretativa de aquél artículo de la LOPJ por el cual circunscriba la razonabilidad de la exigencia de competencia lingüística al modo del Tribunal Supremo, y al modo por él mismo previsto en las SSTC de los años 1983 y 1986, esto es a los puestos que garantizan el derecho de 
opción lingüística del ciudadano, por lo que pudiera ser razonable exigirla para los puestos que permitan hacer efectivo el uso oficial de la lengua autonómica al que aludía en la del año 1991. De esta suerte no acoge del todo el TC la doctrina del TS - los funcionarios que deban atender a los ciudadanos, directamente o tramitando sus expedientes- sino un criterio más amplio y flexible sobre que un puesto precise el conocimiento de la lengua autonómica. Pero en todo caso se ha de justificar la necesidad a la luz del puesto.

Por lo demás, ya hemos constatado que para el caso de que la competencia idiomática sea exigible, el grado de la misma debe guardar relación con las funciones del puesto.

Parece pues que el TC aceptó la constitucionalidad de una norma que imponía el conocimiento general de la lengua regional con base a la situación sociolingüística catalana, pero que ello no implicaba una medida de normalización de manera que fuera exigible para todo los puestos un nivel mínimo de catalán con independencia del contenido del puesto y la función, esto lo califica de discriminatorio. 


\section{Crónicas y Documentos}

REALA-2007, núm. 304. PATRICIA FABEIRO FIDALGO. EL PESO DE LAS LENGUAS COOFICIALES EN EL ACCESO A LA... 